\title{
Report to APSA Council
}

\author{
Publications Planning Ad Hoc Committee
}

$\mathrm{P}$ ublications are one of the most valuable and extensive services that professional associations provide to their members. APSA is no exception; among other things, its publications present research findings, help scholars find jobs, encourage innovative teaching, inform members of the association's actions and individuals' promotions, and help people to publish. This rich and vibrant array of materials has grown incrementally over time and has evolved to satisfy new needs, instantiate new visions, or respond to new contingencies. It works extremely well for many purposes, but perhaps not for all. Furthermore, the existing array may not be well suited to transformations now occurring in the technology of conveying information and ideas, teaching and learning, research methods and collection of evidence, public outreach, or political scientists' professional needs. It is time for APSA to stand back and take a broader view of its publications portfolio; hence, this committee.

In September 2012, the APSA Council mandated the creation of a Publications Planning Ad Hoc Committee. It requested that President Jane Mansbridge

appoint a special planning committee charged to look broadly at all the opportunities and issues, including those raised by the Publication Committee's report, and the wider issues of member need, electronic media opportunities, and the appropriate future of the different publications and communications of the association and report back to the Council with a recommendation as to how to proceed.

The formal charge to the Publications Planning Ad Hoc Committee was:

to look broadly at the needs, opportunities, and issues for the future of scholarly publications and communications of the association, and to make recommendations for new initiatives or changes in approach. In conducting its analysis, the committee will want to consider the evolving technologies and formats for electronic media and open access, the formats and editorial arrangements for the existing publications and communications of the association, including standing journals, eNewsletters, organized section journals and newsletters, ideas for eJournals, and the future prospects for the editorial arrangement and structure for PS: Political Science and Politics. The committee should also consider how the APSA scholarly journals are balanced regarding the needs of scholarly production, research audiences and teaching, junior faculty and emerging scholars, association members, press and policy makers, and the attentive public.

(APSA Council, October 2012)

The committee was constituted in October 2012. Its members included:

- Larry M. Bartels, Vanderbilt University

- Simone Chambers, University of Toronto

- Derrick L. Cogburn, American University

- Eric Crahan, Princeton University Press

- Yoshiko M. Herrera, University of Wisconsin, Madison

- Jennifer L. Hochschild, Harvard University, Chair

- Macartan Humphreys, Columbia University

- Karen M. Kedrowski, Winthrop University

- Marc Lynch, George Washington University

- Rahsaan Maxwell, University of Massachusetts, Amherst

- Ricardo Ramirez, University of Notre Dame

- Kaare Strom, University of California, San Diego

The committee met twice in person at the APSA office, in January and June 2013, and engaged in extensive e-mail and telephone conversations. At times the committee dispersed into specific working groups; at other points all members participated in the discussions. Polly Karpowicz and Michael Brintnall ably staffed the committee, and we give them our deep thanks. ${ }^{1}$
This report proceeds as follows: We first identify four distinct missions or purposes to which APSA publications do or should speak, and map current association publications onto those missions in order to identify strengths and weaknesses in the extant portfolio. The report goes on to articulate a small set of core values that association publications, collectively, should fulfill. Next, the report identifies stages of the publication process-from idea through presentation and responseand links those stages to the APSA's missions and values. Finally, the report uses this framework to analyze some specific issues facing the APSA's publications portfolio over the foreseeable future. The report offers concrete recommendations for some of these issues; for others, it suggests and offers justifications for several plausible actions. We do not set priorities, since that is the purview of the Council and Publications Committee (among others). Note, however, that some of the recommended or suggested changes will involve considerable financial resources and engagement, so trade-offs among desirable initiatives may be necessary.

We begin with an important observation: the APSA's publications portfolio is not in disarray. The journals are expertly and enthusiastically edited and produce high-quality articles or reports; many goals of association members are met in the variety of publications produced either directly by APSA or by related associations; inevitable budget constraints are not inhibiting important innovations. APSA could continue doing what it is now doing without warranting any serious dismay. Nevertheless, it can do better; technological innovations for research, teaching, and communication are available, goals are expanding, and APSA should not continue publishing only as it has done for some decades. Perhaps the most critical gap lies in the arena of public and government engagement. Although they are not all that is needed, publications should be an important element of that engagement. The goal of the Publications Planning Ad Hoc Committee is to help political scientists communicate even better with each other, 
students, public officials, and the general public worldwide.

\section{MISSIONS AND VALUES}

Missions: Collectively, APSA publications have four missions, or purposes. They are the creation and use of scholarship, enhancement of teaching and learning, career support and development, and public visibility and impact. Note that, although these missions are depicted as distinct pillars in Table 1 for the sake of exposition, they overlap. Political scientists may be engaged in the scholarship of teaching and learning, which would simultaneously create scholarship and enhance teaching. Similarly, a research project may be important to policy makers, practitioners, or the general public, in which case, it will at the same time create scholarship and have public impact. Arguably all APSA publications contribute to career support and development. Thus the four missions are conceptually distinct, but most individual members engage with several or all of them-sometimes in the same endeavor.

The first panel of Table 1 identifies current association publications in terms of each mission to provide a baseline of where APSA is now and to begin the discussion of possible new or modified publications and publication strategies. The second panel similarly locates current publications that are not officially sponsored by APSA, but that are produced by groups or organizations closely linked to the association. They provide an essential context for thinking about any reconfiguration of APSA output.

Each cell is populated; there are no glaring empty spaces. However, there are some discrepancies. For example, the association does not have a journal dedicated to teaching, whether understood in

Table 1

\section{Current APSA and Closely Associated Publications, Mapped onto Association Missions PUBLICATIONS DIRECTLY UNDER THE AUSPICES OF APSA}

\begin{tabular}{|c|c|c|c|}
\hline CREATION AND USE OF SCHOLARSHIP & $\begin{array}{l}\text { ENHANCEMENT OF TEACHING AND } \\
\text { LEARNING }\end{array}$ & CAREER SUPPORT AND DEVELOPMENT & PUBLIC VISIBILITY AND IMPACT \\
\hline $\begin{array}{l}\text { American Political Science Review } \\
\text { Perspectives on Politics } \\
\text { PS research reports and symposia } \\
\text { Conference papers at SSRN } \\
\text { Presidential task force reports }\end{array}$ & $\begin{array}{l}\text { PS: The Teacher section } \\
\text { Teaching Conference: } \\
\text { - papers at SSRN and on APSA } \\
\text { Connect } \\
\text { - track summaries } \\
\text { - APSA Connect discussion } \\
\text { - syllabi reviews and collections } \\
\text { Task forces: } \\
\text { - syllabi } \\
\text { - teaching materials }\end{array}$ & $\begin{array}{l}\text { PS: professional news sections: } \\
\text { - The Profession articles } \\
\text { - People section } \\
\text { - Association News } \\
\text { - Briefs } \\
\text { - Washington Insider section } \\
\text { eJobs (online and monthly ejournal) } \\
\text { and Placement Interview Service } \\
\text { APSA reports: } \\
\text { - membership surveys } \\
\text { - department surveys } \\
\text { - reports to department chairs } \\
\text { - placement reports } \\
\text { eNewsletters (APSA individual } \\
\text { members, department chairs, } \\
\text { graduate students) } \\
\text { APSA website } \\
\text { APSA Connect } \\
\text { Member directories } \\
\text { APSA studies of the profession }\end{array}$ & $\begin{array}{l}\text { Perspectives on Politics (some } \\
\text { items) } \\
\text { APSA and Cambridge press } \\
\text { releases and events } \\
\text { Task forces: } \\
\text { - reports } \\
\text { - online forums } \\
\text { - press events } \\
\text { - public website and online } \\
\text { resources } \\
\text { MediaConnect } \\
\text { PoliticalScienceNow.org }\end{array}$ \\
\hline \multicolumn{4}{|c|}{ PUBLICATIONS UNDER THE AUSPICES OF GROUPS ASSOCIATED WITH THE APSA } \\
\hline CREATION AND USE OF SCHOLARSHIP & $\begin{array}{l}\text { ENHANCEMENT OF TEACHING } \\
\text { AND LEARNING }\end{array}$ & CAREER SUPPORT AND DEVELOPMENT & PUBLIC VISIBILITY AND IMPACT \\
\hline $\begin{array}{l}\text { Section journals (currently 18) } \\
\text { Journals of related scholarly } \\
\text { societies (e.g., AJPS; ISQ; Politics, } \\
\text { Groups, and Identities) } \\
\text { Subfield or specialized journals } \\
\text { from nonprofit or commercial } \\
\text { publishers (e.g., World Politics; } \\
\text { Political Theory; International } \\
\text { Organization) } \\
60+\text { related organizations hosting } \\
\text { panels at the APSA annual meeting. }\end{array}$ & $\begin{array}{l}\text { Journal of Political Science } \\
\text { Education } \\
\text { H-Net e-mail listservs } \\
\text { Sections: e.g. } \\
\text { - syllabi collections } \\
\text { - libraries } \\
\text { - e-mail listservs } \\
\text { APSA annual meeting short } \\
\text { courses, sponsored by individuals, } \\
\text { sections and related groups. }\end{array}$ & $\begin{array}{l}\text { Sections: } \\
\text { - e-mail listservs } \\
\text { - APSA Connect discussion and } \\
\text { document libraries } \\
\text { - public/members-only websites } \\
\text { and online resources } \\
\text { - newsletters }\end{array}$ & $\begin{array}{l}\text { Political science blogs, e.g. } \\
\text { - The Monkey Cage } \\
\text { - Crooked Timber } \\
\text { - Political Violence at a Glance }\end{array}$ \\
\hline
\end{tabular}


terms of research on teaching and learning (which might be appropriate for one of the research-oriented journals), teaching materials and techniques, or other analyses of how best to convey political science knowledge and methods to students. The association also does not have any publication through which members can regularly and systematically engage the public as, for example, independent blogs do. APSA staff, rather than political scientists in colleges and universities, are mainly responsible for the public face of political science; that is an arena for further growth and innovation.

As the Council and association members consider changing or adding to the mix of APSA publications, we note that the professional associations of both philosophy and of the four social sciences most similar to political science-economics, sociology, academic psychology, and anthropology-each publish more and a broader array of journals. Economics has journals analogous to the American Political Science Review (APSR) and Perspectives on Politics, as well as a standalone journal of book reviews and review essays, and four subfield-specific research journals. Sociology publishes journals analogous to the APSR and Perspectives on Politics, as well as a stand-alone journal of book reviews and review essays, and five subfield research journals. The American Sociological Association (ASA) also publishes a journal on Teaching Sociology, and a magazine with material analogous to the career development sections of PS. The American Anthropological Association publishes a flagship journal and a monthly newsletter; it oversees 21 more specialized journals analogous to APSA section journals. Book reviews remain within the main disciplinary journal. Setting aside journals for clinical psychologists, the American Psychological Science Association (APS) publishes the flagship research journal, a magazine analogous to $P S$, and four other journals. Two present research findings or current issues in a format appropriate for teaching or the general public, one presents book and integrative reviews and theoretical statements, and one focuses on advances in clinical science. In philosophy, individual faculty founded the leading journals and ownership typically resides with publishers or a society formed for that purpose. In 2015, the American Philosophical Society will launch a new general journal published by Cambridge University Press as a digital only publication.

APSA need not follow the model of other professional associations, but we offer these examples as a way of suggesting that the discipline of political science has some maneuvering room to rethink aspects of the link between its missions and its publications.

Publication Values: In addition to its concrete missions or purposes, the committee identified four broad values that APSA publications individually and collectively ought to sustain. Some values may be especially relevant to some publications or missions, but all should be considered when assessing existing and possible new APSA publishing activities. These values are:

Opportunities for Authors: This value focuses attention on opportunities to publish using a full array of methodologies or types of research on a wide array of topics. It signals the value of encouraging scholars of all ranks and backgrounds to publish, and the prospect that new ideas, approaches, and themes are welcomed into the scholarly domain. It recognizes that publication in an APSA outlet sends a signal about quality and relevance of the author(s) to other scholars, employers, policy experts, and the public. The value of opportunities for authors also encompasses support for innovation in content and form of publication, in strategies for presenting new material, and in efforts to expand intended audiences. Finally, there are opportunities for the association as well as for authors, since journals and other publications help to organize the discipline as well as vice versa.

Investigation for Users: This value focuses attention on the need for ready access to publications of various kinds, both within political science and beyond it in related or relevant disciplines and through public documents and data. It also draws attention to the ways in which published work advances knowledge. There are at least three elements in successful investigation: availability of materials (e.g., through open-source docu- ments), navigability (e.g., through development of a high-quality database), and the generative capacity of the work itself for suggesting further avenues of investigation.

The value of investigation also emphasizes ease and comprehensiveness when users navigate through APSA publications-for example, being able to reach databases or archives, authors' websites, blogs or news releases, teaching tools, curated online bibliographies, and slides or videos, all through electronic links within a given article. Finally, investigation includes active dissemination of scholarship to a wider audience outside the discipline, so that others can explore the content and concepts in political scientists' work.

Integration: From an author's perspective, the value of integration encourages a publication strategy in which scholars can work with a single research project to satisfy multiple APSA missions (e.g., a research-based article, a teaching tool developed from evidence in the article, a blog posting about the research, a video or interactive website using the evidence in the article, a dataset, and a peer-reviewed policy brief). From a user's perspective, the value of integration encourages a publication strategy in which a reader can bring together various publications that satisfy a single purpose, such as multiple blogs or presentation slides for a public lecture, or a set of simulations and interactive websites for a course.

Quality: The APSA "brand" must convey the quality of a publication, typically, but not necessarily, through peer review. Scholars should be able to rely on the APSA brand to assure employers, other researchers, and the public that an innovative or unusual presentation in a publication (such as a blog or video) is to be applauded, not treated as a lack of serious purpose or lack of quality control. In addition to peer review or vetting by the APSA staff, indicators of quality might include a research registry, a journal editors' requirement or encouragement to make research materials available for further analysis, encouragement of articles that 
replicate (or fail to replicate) previously published scholarship, and an APSA-vetted list of publications from related disciplines that pass a stated threshold of quality.

In short, APSA publications should encourage a wide array of ideas and persons, make it easy for readers to investigate relevant materials and new ideas, encourage authors and users to integrate across missions and modes of publication, and convey that an APSA publication reaches a high level of quality. These values are not sharply distinguished from one another conceptually or empirically, but they do emphasize different aspects of an excellent publications profile. Each will play out differently across the four missions of APSA publications, but there is no reason that any should be sacrificed at any point in the publication process.

\section{ISSUES IN PLANNING AND} DEVELOPING APSA PUBLICATIONS

Stages of Publication: In order to think systematically about the missions and values of APSA publications, the planning committee identified four stages of the publication process itself. These are:

Production: At this stage, scholars and APSA staff create and analyze the data, delve into the archives, develop the philosophical concepts, engage in field work, experiment in the classroom, or do whatever else is needed to generate the relevant publication. With the crucial exception of material produced by APSA staff, most of this work is done outside the direct purview of the association. Nevertheless, APSA plays a critical role in enabling the production of scholarship, teaching materials, and public outreach, as well as of assistance in professional development. Association activities at the production stage include, but are not limited to, the annual convention and teaching and learning conference, establishment of the Social Science Research Network (SSRN) site for pre-publication papers, small grants for travel and for research in Washington, DC, use of the Centennial Center, membership surveys, funding for studies of the profession, and expressions of support for National Science Foundation (NSF) and other funding agencies.
Pre-publication Evaluation: After a draft publication is produced, it is evaluated; the goal here is to promote the value of quality. The main form of pre-publication evaluation is peer review, combined with evaluations by journal editors and editorial boards. The system of peer review is well established and has many virtues; it also has problems. Pre-publication evaluation also may include discussion within the APSA staff, discussants' comments at conferences and in online forums, and direct communication with colleagues.

Dissemination: This is the stage of actual publication, but we use the broader term dissemination in order to make it clear that "publication" extends beyond the traditional format of printed (or online) documents in established journals or reports. These are crucial, but dissemination increasingly takes other forms as well, such as blogs, online-only journals, e-mail listservs, and public forums. Dissemination also includes placing data or other evidence in a repository available to other scholars, testimony before legislative or expert panels, multimedia shows, perhaps museum exhibits, policy analyses for a client, and so on. This is the stage of the publication process at which the four central missions of APSA come to the fore; dissemination may take very different forms depending not only on content but also on audience and purpose.

\section{Engagement and Post-publication} Evaluation: This is an arena ripe for further development within the APSA publication portfolio. At this stage, authors and readers connect directly or indirectly. Engagement may take the traditional form of book reviews and symposia on published articles or books, perhaps supplemented by reviews of websites, datasets, archives, museum exhibits, movies or videos, teaching simulations, syllabi collections, curated reference and bibliographic materials, and so on. Engagement and evaluation also may take the form of blog posts about a publication, a forum offered by a journal for online discussion and comment (with or without editorial control or peer review as a certification of quality), reports on efforts to replicate a study, and reports of the effectiveness of APSA publications in classrooms. The goal of engagement and post-publication evaluation is to facilitate the values of investigation for users and integration as a means toward the production of new knowledge and ideas-thus beginning the cycle again.

Almost all APSA publications involve production, pre-publication evaluation, and dissemination; an increasing number include engagement and post-publication evaluation. APSA directly or indirectly facilitates all four stages, but we turn now to suggestions of ways in which it could do more or better. We present these issues in two clusters, ordered by stages of the publication process, without setting priorities with regard to urgency or importance. On some issues we make specific recommendations; for others, we offer options for possible action by the Council, Publications Committee, association staff, or journal editors.

\section{Production and Pre-publication Evaluation}

Broadening the Definition of Research and the Style of Publication: We encourage APSA and journal editors to treat the scholarship of teaching and learning as a legitimate area of scholarly inquiry in political science, and to consider how to incorporate such studies into APSA's family of publications. For instance, the ASPR and Perspectives on Politics do not prohibit manuscripts on the scholarship of teaching and learning, but they are seldom encouraged or solicited. New publications, whether electronic or print, provide an excellent opportunity to integrate the scholarship of teaching and learning into the rest of the discipline by publishing high quality empirical studies and teaching materials such as research-based simulations. (See also our discussion of the possible future of $P S$.)

The committee also encourages further development of journal editors' ongoing efforts to ensure that the opportunity to publish is equally accessible to all substantive fields, methodological approaches, normative stances, or research questions. Correctly or not, some political scientists worry that political science journals privilege quantitative and 
formal methods, the study of American politics, or mainstream political science (however defined) over interdisciplinary work, topics in emerging or smaller subfields, conservative viewpoints, or studies focusing on race, class, gender, and sexual orientation. Some believe that faculty at $\mathrm{PhD}$ institutions receive better treatment than do independent scholars or faculty at non-PhD-granting institutions.

Such perceptions or actual biases can create a self-perpetuating cycle if they affect decisions about submission to journals, make it more difficult to find reviewers, or encourage reviewers to recommend that a submission go to a specialized journal or even one outside political science. Any of those outcomes can, in turn, further reduce the visibility of some kinds of scholarship within the discipline. The committee therefore recommends that APSA develop an assessment of these perceptions and publicize its findings widely. We have not developed a detailed strategy for such an assessment; perhaps experts outside the discipline (or political scientists outside the academy) should conduct it, given the sensitivity of the issue and the difficulty in reaching a persuasive conclusion. If an assessment does show unrecognized bias at any stage of the publication process, APSA might consider providing training for editors, editorial assistants, and reviewers to work against it. With or without a systematic assessment, we endorse editors' continued efforts to broaden the array of articles they publish, along a variety of dimensions.

Finally, we urge more attention to the range of possibilities encompassed by an "article" or a "publication." On one end of the spectrum, on-line materials as part of or accompanying an article could include reproductions of archival material, maps, interview transcripts, musical selections, videos, or other types of evidence impossible to include in a printed journal. On the other end of the spectrum, journals might experiment with brief formats-a several thousand word report of a new finding; a 1200-word "viewpoint" paper that addresses an important topic in political science, politics, governance, or public policy; or even a 6oo-word "research letter" reporting original research. ${ }^{2}$

Enhancing Peer Review: Pre-publication reviews both help to improve draft manuscripts and provide an essential element of quality control. The value, equity, inclusiveness, and timeliness of reviews speak to core publication values-opportunities for authors and quality-and to the missions of creating scholarship and supporting career development. The peer-review process also is a crucial element of broadening the definition of research, since new pools of reviewers might be essential for evaluation of different kinds of work. As expectations for publication in top disciplinary journals rise and as the number and variety of political science publications increases, however, the process of pre-publication evaluation comes under greater pressure. Three related issuesreviewer fatigue, reviewer exclusion, and double-blind reviews-seem especially worthy of consideration.

We know of no data to determine the accuracy of this perception, but many political scientists are concerned that some scholars are asked to review disproportionately while others are not invited to do so. Journal editors sometimes cannot get the scholars considered most distinguished in the field to review because they are overcommitted; editors sometimes have to make repeated requests before getting a sufficient number of reviews. The problem may be most acute in emerging fields, specialized methodologies, and interdisciplinary research. Conversely, some active political scientists are not requested to do reviews despite being willing and able to do so. These members are perceived to be disproportionately in lower-ranked or teaching-oriented departments; some also may have removed themselves from the publication process because they believe there to be biases against particular topics.

The committee sees four remedies that are relatively easy to implement. We also encourage journal editors to experiment with other responses to the apparent problems of overinclusion and underinclusion. First, APSA could facilitate a more systematic search for qualified and underused reviewers. The association, or a set of journal editors, could establish a joint archive of scholars who are promising reviewers, for example, those who have recently published in the field or who have been recently tenured. Recruitment at annual or regional meetings and in sections could be a source of names for the archive. Editors and graduate editorial assistants could be trained to look in nontraditional places-for example, in community colleges or public agencies, and among independent scholars. Identifying all APSA journal articles and all potential reviewers through a common set of keywords would help in establishing and developing this archive. APSA's membership renewal form could also include a screen inviting people to suggest themselves as reviewers, using the common set of keywords. The archive could include information about how often a person has been asked to review, has accepted or declined, has completed reviews on time, and has submitted manuscripts to journals for review.

Second, editors could engage in more extensive internal review, including a more aggressive use of desk rejects. ${ }^{3}$ This implies a greater burden on editors and more editorial control; a more extensive use of broad editorial teams or an active editorial board could help with both concerns. Since more internal editorial review challenges the traditional assumption of external, blind peer review, it should be used judiciously and with a transparent set of decision rules. Journal editors might agree to some sort of external review of their procedures and decisions after a certain period of time to assure themselves and others that decisions about desk rejects are appropriate and fair. The association might investigate the training programs used by the NSF and National Institutes of Health (NIH) to decrease unintentional biases.

Third, publications could seek further ways to simplify and streamline the review process. Most editors already remind reviewers about deadlines and take considerable pains to get reviews in on time. Editors might experiment with more closed-ended reviews, although this risks approaching a multiple-choice formatwhich would be more efficient but less effective. We urge the association or the Publications Committee to canvass other disciplines and academic book publishers, and develop a set of suggestions or best practices from them.

Finally, the committee encourages APSA to articulate a set of norms for departments about pre- and post-publication evaluation to incorporate into their tenure and promotion criteria. Training as peer reviewers, conducting peer reviews, and contributing commentary or online dialogue are increasingly valued professional responsibilities. The goal here is to encourage departments and universities to expand their understanding of faculty productivity and disciplinary engagement; doing so would contribute to the 
mission of career support and development as well as improving the quality of evaluation in APSA publications.

The committee also considered more substantial changes in the review process. Some journals in other disciplines, for example, are experimenting with asking authors of rejected manuscripts if they want the reviews passed on to another journal. The logic here is that an article might be well suited for a specialized journal or a different journal than the one to which it was submitted, and the same reviews might yield a "revise and resubmit" or possibly even acceptance in a different publication context. Committee members raised concerns about this practice, so we would recommend proceeding with caution. Another possible innovation would be transforming reviews, where appropriate, into published commentary on an article. That would encourage highquality reviews and may provide an incentive for reviewers to respond more quickly. However, it would require editors to make an additional set of complicated decisions, and could slow publication if the review being transformed into a commentary requires revision, or itself calls for review. Again, this is a suggestion rather than a committee recommendation.

The issue of double- or single-blind peer review is probably a question for journal editors or the Publications Committee to decide, but the planning committee offers two plausible positions for further consideration. On the one hand, while the system of double-blind reviews has problems, it has offsetting virtues. Reviewers might know authorship of some manuscripts owing to presentation of a paper at conferences, an article's availability on SSRN or other websites, or simply a Google search. Nevertheless, studies have documented that gender and ethnic bias in evaluation can occur even when only names differ, for example, an article by "Tanya Juarez" might be evaluated differently than one by "Thomas Jones." Given this, it would seem that allowing reviewers to see an author's name could introduce bias without any clear benefit.

On the other hand, APSA journals might consider going to a single-blind review process, as the economists have done. Since the identity of most authors is only a Google search away, an author's name and identifying information are rarely in doubt to a reviewer who wants to know. The issue of gender, ethnic, and other biases, which is real, could be better addressed through the editorial teams and the monitoring of some key factors, much as is already done with field coverage and balance. Furthermore, moving to a singleblind review process would eliminate confusion and ambiguity. At present, editors and the author(s) must guess whether the reviewer did the Google search or not, and then must guess about how much that possible Google search did or did not influence the review. A single-blind review process would leave no ambiguity about what reviewers know about an author; after a few years, the association could analyze whether gender, ethnic, smallschool, or other biases have been introduced or exacerbated. More speculatively, the author(s)' identity conveys some useful information to reviewers regarding at least the prior perspective and biases of the author(s) or the quality of the analysis and interpretations; again, knowing that this information is available to a reviewer can help all parties evaluate the context from which a review is written. Note that it would be important for journal editors to make clear to writers and readers alike just what is "blinded" and to whom.

In general, pre-publication peer review remains the gold standard for enhancing the production of scholarship and assuring the quality of articles and reports. Peer review will only become more complicated as the association moves toward a more differentiated set of publications or engages with new technologies for presenting material, so some discipline-wide discussion of how to do it effectively, efficiently, and fairly would be valuable.

Registration Standards: Research analyzing the distribution of test statistics in published articles suggests that political science suffers from severe reporting or publication bias. Results are much more likely to make it into print if they reach significance levels just above critical cutoffs of $90 \%$ or $95 \%$, and less likely if they fall just below these thresholds. This raises concerns about the quality of articles in the discipline's journals.

For one thing, individual published results may be wrong; if estimated effects are only published conditional on being "statistically significant," then these estimates are likely to be overestimates. In addition, even if all individual published estimates were correct, the systematic underreporting of null results would produce an inaccurate record of general effects. That is, scholars, students, and external audiences will start believing that $\mathrm{X}$ causes $\mathrm{Y}$ because they only read studies in which $\mathrm{X}$ causes $\mathrm{Y}$, not studies in which it does not. Furthermore, pressures to generate significant or counterintuitive findings can induce researchers to condition their analysis strategies on patterns they observe in the data; that, in turn, can lead to intentional or unintentional data fishing. The result is false and fragile findings.

One response is registration standards, in which researchers describe and make public the analyses they plan to conduct before seeing the results of those analyses. Creating a public record of intended analyses reduces the scope for adjusting analysis plans to select for significant findings, and creates a record of studies in a given area even if the published record is not representative of that population.

Registration is now the norm for experimental research in medical sciences; major medical journals now treat registration as a precondition for publication of results from a randomized control trial. The American Economic Association has recently launched a registration tool (socialscienceregistry .org). The research funding group zie has launched a registry in the area of development economics. Informally, individual researchers have been registering designs in political science through the website of EGAP (Experiments in Governance and Politics, e-gap.org) or through Harvard University's Dataverse (http://dvn.iq .harvard.edu/dvn/).

This committee recommends that APSA develop a set of principles on registration for adoption by the Publications Committee or individual journal editorsand, hopefully, by other political science journals. To this end we highlight several considerations that will help to ensure that APSA's registration principles are consistent with the needs of the broader discipline:

Scope: Registration is not appropriate for all kinds of research; it is intended for studies that seek to test major theories. Such studies could be experimental or observational, quantitative, or qualitative. Registration may not be appropriate for political philosophy, methodological contributions, ethnographies and other inductive research, or interpretivist analyses. 
The association and journal editors need to ensure that registration is not presented as a general sign of quality for all types of research, nor can they allow support for registration to be interpreted as promoting one research approach over others.

Discovery: A core part of political science research is exploratory. Registration may help to delimit hypothesis-testing research from more exploratory work, but the association and editors need to ensure that adoption of registration standards does nothing to devalue or inhibit exploratory work.

Flexibility: Some have expressed concern that registration will inhibit researcher flexibility; for example if researchers implement analyses that they come to believe are flawed simply to remain consistent with a previously developed strategy. An appropriate registration system should enable adjustment of plans in response to new knowledge, while preserving the transparency-enhancing benefits that are its goal.

Nonexclusiveness: Even if journals implement registration standards, they need to be careful not to diminish the use of other vehicles for quality control of publications. Those vehicles include transparency with regard to solicitation, review, and selection of articles (for example, in invited symposia); norms requiring functioning data sets with proper documentation for replication; journals or sections of journals devoted to replication studies; and clear rules about how to ensure quality in articles based on confidential interviews, interpretivist analyses, or normative arguments.

\section{Dissemination, Engagement, and Post- publication Evaluation}

Expanding Channels for Dissemination, and Incorporating Technological Innovation in Presentation: We encourage everyone involved with APSA publications to continue working to expand channels for disseminating publications to new audiences or to extend dissemination and integration among current APSA members. However, the association does not have a mandate to develop the technology for innovative distribution and, given inevitable budget constraints, the committee considered but does not recommend hiring an in-house technology expert (beyond those already on the staff). Therefore we suggest an alternative way to promote technological innovation in broadening and deepening the audience for publications - a small grants program or annual awards (one each at the two annual conferences) for the most exciting or useful innovation in enriching APSA publications' readership. The goal of the grants program or awards would be to facilitate and reward experiments in dissemination and outreach, highlight their importance to authors and users, provide a signal to employers, and spread the use of especially promising ideas.

We also encourage the continued expansion of online publication of APSA products. "Online" does not mean that editors give up the important curatorial task of putting issues together with themes having coordinated content and sustained treatment; it does, however, open possibilities for expanded readership and electronic integration across items and journals. Editors might choose to post articles online on a rolling basis (see, for example, Oxford University Press's new strategy for presenting chapters in its Handbooks series), or they might decide that the journal issue goes live only when all parts are in place and connected through a table of contents or editor's introduction articulating their connections. Different publications might experiment with different choices about the timing of release, and about the appropriate iteration of online and print publication.

Incorporating technological innovations in dissemination is closely linked to, but not identical with, incorporating technological innovation in presentation of ideas and findings. On the one hand, scholarly content increasingly employs formats beyond the traditional modes of journals and books (and even these traditional publication routes can be enhanced with new media and online features). On the other hand, APSA has neither the responsibility nor the resources to go very far down the road of developing these new formats or features. Thus the committee comes down in roughly the same place with regard to new forms of presentation as it did with new forms of dissemination-a suggestion for small grants or awards at the two annual conferences, with the goals of signaling quality to readers and employers, encouraging new ideas and experiments in presenting research findings, and making the best innovations widely visible. For both dissemination and presentation, we note the importance of the forthcoming Presidential Task Force on Public Engagement as a source for ideas, expertise, and research findings.

The Future of PS: The planning committee recommends consideration, presumably by the Publications Committee and APSA staff, of possible restructuring of PS. The journal's current mission combines research on teaching and learning in political science (some items peer-reviewed), symposia and peer-reviewed research articles about currently important political and policy issues, articles about the discipline of political science (some items peerreviewed), and news about individuals, departments, and the association. Each component serves an important function, but each is sufficiently distinct that they need not be united in one publication. Arguably each element of $P S$ 's mission would be best served by separating them.

First, news about individuals, departments, and the association should remain within APSA staff oversight. That publication could become online only, with electronic links to the websites of the individuals or organizations mentioned or to other online material. It could also include "columns" (that is, regular contributions) or guest reports by an array of political scientists-inside and outside the academythat surveyed, reviewed, and generally kept track of the blogosphere and other technological innovations. Ensuring that many of the contributors are located outside the United States might expand APSA's international reach.

Second, components that focus on teaching and learning could become a stand-alone journal, with an editor and editorial assistants at a teaching-oriented college or university analogous to the editorial set-up of Perspectives on Politics and the APSR. Such a journal should be available online, and perhaps be online only; along with peer reviewed articles, it could usefully include links to syllabi collections, simulations or other teaching tools, and datasets or other resources useful in a classroom. Further details of developing that publication would evolve during the recruitment of an editor and editorial board. 
Third, the excellent contributions to the research section in $P S$ may not be receiving the readership they deserve since they appear in a publication whose profile is mixed. If $P S$ were reconfigured, research articles and symposia could be incorporated into one of the existing journals, or-since they tend to be brief, accessible, and current-they could become part of a new publication focusing especially on public visibility and impact. Alternatively, if the association creates its own blog or develops ties with extant political science blogs (see discussion below), the research section of PS could be migrated there. Finally, some or all of the research symposia now in PS might be appropriate for the APSA's new e-journal, depending on whether it is developed and how it is configured.

The Future of Book Reviews: The question has been raised about whether book (and other) reviews should remain within Perspectives on Politics or be located in a stand-alone journal. The committee did not come to a clear conclusion on that issue. We have several reasons for abstaining from a recommendation: some disagreement and ambivalence within the committee; deference to the current editor's clear vision, combined with a recognition that future editors might develop a different vision; a sense that this decision belongs in the purview of the Publications Committee and possible future editors; and recognition of the interdependence of several choices about APSA publications. There is no immediate reason to decide about a change, and other publication issues arguably have greater priority or urgency.

A decision about the appropriate place for reviews should be put into the context of a broader debate about the identity and purpose of Perspectives. The current motivating vision for the journal is as a "political science public sphere"; the review essays, critical dialogues, and research articles are all aimed at creating a rich discourse within the broad and fragmented field of political science. In this vision, book reviews and symposia enable members of the discipline to publicly discuss big ideas presented at book length, and they are often the main way for political scientists to stay abreast of new topics and debates. Removing reviews from Perspectives arguably would diminish and narrow its vision and effectiveness.

An alternative identity and purpose of Perspectives might be to pursue a broad readership outside as well as inside political science, i.e., to seek to engage a politically or policy-oriented public. In this conception, Perspectives would focus more on publishing articles of broad public interest and relevance, and less on cultivating an internal political science public sphere. An extensive set of reviews of academic books is less essential to the mission of public engagement, and could even deter potential readers outside the academy. (We note, nonetheless, that magazines such as The Economist and The New Yorker publish a few reviews or review essays in each issue, so a newly configured Perspectives might well include selected symposia or review essays.)

This sort of redirection of Perspectives, or other alternative visions, would likely imply shifting the composition and focus of the articles published in the journal. Any decision about Perspectives' future, and therefore about the role and location of reviews, needs to be interdependent with current APSA discussions about launching an e-journal, or future discussions about engaging more actively in the blogosphere or moving research articles and symposia from $P S$ to another APSA journal. Even if the current model remains in place, the committee urges even more attention to innovative ways of presenting book and other reviews online. Debate and dialogue might be further encouraged, for example, through moderated comments and structured discussions involving reviewer(s), author(s), and readers. As we noted above, other material could be reviewed, such as museum exhibits, movies, websites, datasets, and archives. Investigation for users as well as integration across items and journals could be enhanced by imaginative and more extensive use of the capability for electronic links. Note that these or other innovations should occur in the context of a broader move toward creating online interaction as a core part of APSA journals, not as something directed at Perspectives in particular.

Perspectives is a healthy and well-liked journal, which is not in evidently urgent need of reform. The decision about reviews in Perspectives, therefore, depends mainly on how the association decides to pursue broader public engagement and how it understands the mission of the journal-as well as, of course, preferences of current and future journal editors and authors. This is another arena in which attention to the choices of other disciplines could be illuminating, since they cover a wide range of options. Sociology, economics, education, and psychology have stand-alone review journals (the latter is online only); history has both a stand-alone journal of review essays and reviews in the two flagship journals. Reviews are integrated into the flagship journals of anthropology, American studies, and public administration. Anthropology is considering development of a digital platform for book reviews. Furthermore, APSA sections and other political science professional associations or publishers are experimenting with various forums for reviews, ranging from inclusion in the central journal to stand-alone online reviews that roll out when complete.

Stand-alone journals have more space for review essays, symposia, or additional reviews and can be more flexible with regard to timing and format. But it would be important to determine how widely they are read, whether they are read in relation to each other, and how much intradisciplinary engagement they generate. Financial considerations will also matter, although they are outside the purview of this report.

Open Access: Scholars like open access because they want others to find, disseminate, and use their work. Open access to journal articles can enhance teaching and learning, generate public visibility and impact, and foster a career if an author can show interest in his or her writings to deans and departments. Open access enables students and scholars around the world to benefit from the resources enjoyed by political scientists in well-off colleges and universities, and can spur international dialogues even wider than Perspectives' political science public sphere can currently hope to do. The United States' federal government and the national governments of other countries are making increasingly strong demands that data or publications from publicly funded research be made publicly available.

Under current financial arrangements, however, open access can be cost prohibitive. The rough rule of thumb is that the average revenue to journal publishers per article in traditional publications is $\$ 5,000$; publishers will not, and cannot, relinquish all of that revenue. Neither can scholarly associations, whose income depends in large part on contracts with publishers that, in turn, rely on subscriptions to journals. In short, the question of open access 
raises broad and deep issues, leading one expert to claim that "a comprehensive OA paradigm is pretty much a frontal assault on professional societies" (http:// scholarlykitchen.sspnet.org/2013/o8/01 /open-access-and-professional-societies/).

APSA and its members need a much more developed analysis of the financial, legal, and intellectual implications of open access than this report can offer before concrete recommendations are made. We therefore limit ourselves to endorsement of the principle of open access-but also to an equally strong urging of the Publications Committee, Council, APSA staff, and others to systematically analyze the opportunities and risks attendant on a regime of open access, especially in light of the other worthy demands on APSA resources.

Ungating Selected Articles: Ungating provides a short-term solution to the desire for open access, before a more extensive policy is developed. Most generally, public engagement as a core ASPA value entails making the highest quality political science research available and relevant to an interested public. But it is unrealistic to expect even interested nonacademics to seek out scholarly journal articles and to overcome significant logistical or commercial barriers to access. Thus real impact will require appropriate platforms and approaches to drive attention to these articles and to convey their significance even in an intensely competitive, information-saturated marketplace of ideas.

Ungating access to journal articles when appropriate to their public discussion is the most obvious step that APSA can take. APSA does work with publishing partners to selectively ungate articles for marketing and promotional purposes; we recommend that it work even more closely with journal publishers to create an easy, smooth, fast, and egalitarian process to allow bloggers to temporarily ungate any APSA journal article about which the blogger is writing. The committee suggests consideration of a two-tiered process: a top tier of pre-approved, established blogs with "green light" power to temporarily ungate articles discussed on their blog; and a second tier that involves a relatively simple and rapid process for noncertified blogs to request ungating.

Blogs: A more extensive response to the issues involved in open access-and an important innovation in its own rightwould be for APSA to encourage and support the trend toward political science blogs.
They can translate disciplinary findings into topical, readable prose in a timely fashion and stimulate informed public discussion of issues. We see three potentially viable models for APSA to support blogs, each with its own problems and advantages. The models are not mutually exclusive: two or three could be pursued simultaneously. Each model provides access to writers and readers, and takes advantage of APSA's ability to brand a publication as high quality. They differ in the degree of commitment of associational resources of time, reputation, and money. These three models are:

\section{Support existing blogs: The cheap-} est and easiest model would be to certify existing blogs (such as Monkey Cage, Duck of Minerva, Foreign Policy, Political Violence at a Glance). Officially sanctioned blogs could display an online badge indicating their APSA recognition and would be linked on the APSA website, without any ASPA endorsement of their content or editorial decisions. Ideally, certification would give these blogs advance access to forthcoming articles and green light power to have those discussed temporarily ungated. This model might involve some APSA financial or administrative support to such blogs, and intermediating efforts with journals, but that is not necessary. A second step might involve creating a committee to nominate existing blogs for official status, or to evaluate candidates following a "call for proposals" to blogs that would like to be considered.

This model has the advantage of not requiring new staff, infrastructure, or a website; it has the disadvantage of relinquishing direct APSA control or oversight of the resulting products. Blogs would need to be identified across all relevant subfields and across ideological or political stances if that is relevant. This model should be inclined toward a relatively large number of officially sanctioned blogs, so that none would be taken by default as the official APSA blog. The selection of APSA-recognized blogs would require clearly articulated criteria for evaluating which ones to certify and would need to consider concerns about exclusion and politicization flagged by Rob Farley in
"Complicating the Political Scientist as Blogger" (PS April 2013).

Journal-based blog(s): A second model would be for APSA journals themselves to be adapted for public engagement and dissemination. The International Studies Association has recently moved in this direction. Its flagship journal, International Studies Quarterly, has named a new editorial team committed to integrating online publication and public engagement into the journal's mission and operations. APSA should watch this experiment closely. On the one hand, the shift toward faster online publication and continuous engagement with each article has raised worries about reviewer and contributor fatigue if the cycle of publication is accelerated. In addition, some might worry about quality control if online traffic metrics become important in guiding editorial decisions. On the other hand, this model could significantly increase opportunities for broader engagement created by the Internet without compromising the core mission of APSA journals. For instance, a Perspectives blog could move its "Critical Dialogues" online and open them to broader participation over a defined period (similar to Crooked Timber's book seminars). An APSR blog could feature short and accessible versions of articles, along with hosting discussions on methodological and theoretical issues relevant to a broad portion of the discipline, including faculty focused on teaching and learning. It could also engage political scientists with issues of current political, policy, or analytic interest.

As part of this model, articles might be presented differently. Journal articles might take two forms: a fully rendered article in the current form and a blog version that presents key arguments and findings in a clearly expressed, accessible form without the usual scholarly apparatus. An author, working with a likeminded editor, would be responsible for producing the accessible version, which would be published in an openaccess, interactive associated website. The online site for the journal should have an active and open discussion section to promote constructive 
discourse around the article's findings, and efforts might be made to solicit discussion and critique (perhaps from the original reviewers).

This model depends on the enthusiastic buy-in of the journals' editorial teams; it would require additional staff and support for those journals from APSA. It might need to be phased in over time if current editorial teams have little interest or competency in moving toward it. The obvious transition point would come when proposals are solicited for new editorial teams: an effective online strategy could be ranked as a key element in evaluation of bids. The transition in $P S$ that we outlined above would be an outstanding opportunity to pilot this model and showcase its possibilities.

APSA blog: The most ambitious approach would be to hire a dedicated, in-house blog team to present and highlight political scientists' research, along with other unique content, on a publicly available APSA website. The APSA blog would be in part a clearinghouse for content generated elsewhere, acting as a gold standard or quality control mechanism in an online world brimming with dubious arguments and evidence. There could be a "front page" of featured pieces selected for especially high quality and public significance, invited brief responses to selected pieces by scholars and public officials with relevant expertise, or systematic peer review of outlets that would make their content eligible for inclusion in the clearinghouse.

This model would have the advantage of putting a public face on APSA research and maintaining in-house control. However, the organizational, intellectual, and political challenges are formidable. It might mean bringing an existing blog(ger) on board, or hiring a new blogger with both the social media and analytic skills to meaningfully represent political science to the engaged public. Much would depend on the capabilities of the editor(s) to collect, catalog (by subfield, policy domain, keywords, etc.), and post links to a wide variety of content. The third model would require a budget for salary and for technical support to maintain a professional and attractive website. Risks include the possibility of political, demographic, substantive, ideological, or methodological concerns over the selection of articles for blogging. The official status of an APSA blogger could also pose challenges in terms of cultivating the unique, distinctive, and credible voice necessary for attracting and sustaining an audience.

The committee does not take a position on which model is most desirable or feasible; among other things, there are complex tradeoffs in budgetary and staffing decisions. We do, however, strongly recommend that the association move toward choosing which of these (or some other) model will best foster quality, career advancement, opportunities for writers and the capacity for readers to investigate, and public engagement and influence.

Regardless of how the association moves with regard to blogs, we further recommend development of a short course or panel to be regularly offered at each of the annual conventions. For scholars who want more public connection, a panel with people who are regularly engaged or who write on blogs could be useful and interesting. Panelists could explain how they got started, ways they make their work more accessible, and mistakes to avoid. A panel could be offered at low cost, and a more extensive short course would pay for itself if there is demand. The association also might see if there is sufficient commitment to develop a public engagement section, which could produce a regular newsletter and be allocated a panel or two at each annual convention.

\section{CONCLUSION}

APSA faces many enticing possibilities and a few concerns. We are in the fortunate position of having no serious problems with the current journals, all of which are in strong editorial hands and are publishing excellent work. Similarly, the APSA staff is expertly generating publications designed to foster professional development, interpersonal exchanges, and intellectual excitement. The major questions facing the association, therefore, are in the realm of "what next?"-how can we best take advantage of the rapidly changing Internet world? How can publications engage more effectively with teaching and learning? How can APSA help political scientists to have more impact on policy makers, politicians, and publics around the world?

The most complex problem facing APSA is negotiating strong pressuresand good intellectual reasons-for open access to our publications without undercutting the financial standing of the association. We urge appointment of a subcommittee of members from both the Publications and Finance committees, or a new ad hoc committee, to delve further into this issue than we have been able to do in this report.

The committee also wants to draw attention to the fact that some recommendations or suggested possibilities in this report will involve considerable financial resources as well as the resources of time, energy, and attention. We flag three in particular: 1) development of one or more blogs associated with APSA or its journals, or certified by APSA as passing a threshold of quality; 2) possible development of a new journal focused on teaching and learning or research on teaching and learning, with an editor and staff analogous to current APSA journals; 3) possible development of a stand-alone review journal, or expansion of the reviews section in Perspectives to include other objects for review, other modes of review, and greater use of possibilities offered by the Internet. Either choice may well involve a new fullor part-time editor.

It remains to be seen how these investments will and should intersect with a new e-journal currently being considered by the Publications Committee, the costs of open access, any recommendations growing out of the new Presidential Task Force on Public Engagement, and other existing or new APSA priorities.

Other recommendations or suggestions in this report involve slightly fewer resources, but they too need careful attention and thoughtful development. They include the possibility of registration standards, revisions in the ways that peer reviewers are chosen or deployed, development of more sophisticated electronic links within and among the journals, and development of new formats for and subjects of publication, among other things.

Throughout all of the innovations and reforms suggested in this report and by the many people with whom we have consulted, the committee urges continued commitment to the multiple missions of APSA publications-creation and use of 
scholarship, enhancement of teaching and learning, career support and development, and public visibility and impact-and to the core values-opportunities for authors, investigation for users, integration, and quality. It is not easy to meld missions, values, constituencies, existing structures, and new ideas, but we have full confidence that APSA will continue to do as good a job in the future as it has been doing up to now. We offer this report in the hopes of contributing to that future.

\section{NOTES}

1. Thanks also to Anastasia Fete and Betsy Schroeder, who ensured that the committee meetings ran smoothly and provided an essential record of discussions.

2. The latter two formats come from JAMA: "Research Letters reporting original research should not exceed 600 words of text and 6 references and may include up to 2 tables or figures. Online supplementary material is not allowed.... Research Letters should be divided into the following sections: Introduction, Methods, Results, and Discussion. Research Letters considered for publication undergo external peer review.... Viewpoint papers may address virtually any important topic in medicine, public health, research, ethics, health policy, or health law and generally are not linked to a specific article. Viewpoints should be well focused, scholarly, and clearly presented.... Maximum length: up to 1200 words of text-or 1000 words of text with 1 small table or figure-and no more than 7 references."

3. Given that the current editor of Perspectives on Politics declines to review up to three-fifths of its submissions, we do not urge that journal to increase this number. In contrast, APSR editors decline to review roughly one tenth of its submissions, so there is room for more internal review, more active use of the expertise on the editorial board, and more desk rejects.

\section{APPENDIX: APSA Resource Allocation}

Earlier in this report in Table 1, the committee mapped the APSA journals, publications, communications, public outreach, and other related association activities and those of groups related to APSA into the four main missions of supporting scholarship, teaching, career/professional, and public. The report also notes four main values: 1. Opportunities for Authors, 2. Investigation for Users, 3. Integration, and 4. Quality. Potential areas of growth or reallocation of funds and efforts begin to emerge when we map these missions and values to the association's current publications and related activities.

APSA resources generally align in the following ways:

- APSR falls largely in Scholarship, with a presence in Public Visibility, and supports values Opportunities for Authors, Investigation, and Quality and to a degree Integration.

- Perspectives aligns with Scholarship, with a presence in Public Visibility, and supports values Opportunities, Investigation, Integration and Quality

- PS has a presence in Scholarship, Teaching, and Professional, and supports values Opportunity, Quality and to a degree Integration.

- APSA Task Forces align with Public Visibility and supports values Integration.

- APSA Publications align with Professional and supports Opportunities.

- APSA websites (net.org/APSAConnect/PoliticalScienceNow) map to Professional, Career, Public Visibility and to a certain extent Scholarship. supporting values Opportunity, Investigation and Quality

- SSRN/APSA conference papers support Scholarship and Teaching and supports values Opportunity, Investigation and Quality

- APSA social media presence connects with Professional, Career, Public Visibility and to a degree Scholarship and supports Investigation and Opportunity

The association funds these efforts at the following levels.

\begin{tabular}{lc}
\multicolumn{1}{c}{$\begin{array}{c}\text { ANNUAL APSA BUDGET } \\
\text { (FY13, OCT 1, 2012-SEPT 30, 2013) }\end{array}$} \\
\hline \multicolumn{1}{c}{ EXPENSE } \\
\hline APSR & $\$ 419,654$ \\
Perspectives & $\$ 411,642$ \\
PS & $\$ 319,508$ \\
APSA Publications & $\$ 427,725$ \\
General Journals & $\$ 314,566$ \\
APSAnet.org & $\$ 86,061$ \\
APSA Connect & $\$ 57,035$ \\
Social Media & $\$ 33,835$ \\
SSRN & $\$ 2,000$ \\
Public Outreach & \\
Program & $\$ 53,163$ \\
Task Forces & $\$ 20,000$ \\
Section Journals & Do not have financials \\
& from sections.
\end{tabular}

